\title{
Da retroactividade das leis em materia de impugnabilidade de sentença, jurisdicção e competencia (*)
}

Francisco Morato

A impugnabilidade da sentença ou admissibilidade de recurso contra ella, é uma verdadeira qualidade inherente á mesma, regulada pela lei vigente ao tempo em que foi proferida.

Dahi surge, neste particular do direito transitorio, o primeiro canone, egualmente admittido na doutrina, na legislação e na jurisprudencia, que os recursos contra as sentenças, sobre o ponto de vista de sua admissibilidade e força intima, devem ser exclusivamente regulados pela lei sob cujo imperio foram pronunciadas.

"E quindi canone generalmente ammesso dagli scrittori, dai legislatori e dalla giurisprudenza pratica che $i$ rimedi contro le sentenze devono essere esclusivamente regolati dalla legge sotto il cui impero le sentenze venero pronunciate, e, per conseguenza, che nessun rimedio introdotto da una legge nuova può essere adoperato contro una sentenza emanata vigendo una legge anteriore, che non lo ammetteva, e, per converso, che un rimedio accordato dalla legge sotto il cui impero la sentenza venne emanata, non può venire tolto re-

(*) Mantida a ortografia do autor. 
troattivamente da una legge posteriore". (GABBA: Retroattività Delle Leggi, 1898, vol. IV, pag. 540).

Como, porem, as leis processuaes são de sua natureza retroactivas, surge dahi o segundo canone na materia, a saber, que o uso ou processo dos recursos deve ser regulado, não já pela lei do tempo da prolação da sentença, senão pela lei nova ou do tempo do mesmo processo.

"Non consegue però dall'esposto canone che la procedura da seguirsi nel far uso dei rimedi contro le sentenze debba essere determinata dalla legge stessa, sotto il cui impero la sentenza impugnata venne emanata. Il contrario invece è voluto dal generale canone dell'applicazione immediata o retroattiva delle nuovi leggi procedurali". (GABBA: Ibid. pag. 541).

Estes preceitos, de processo propriamente dicto ou de proceșso no sentido estricto, não são os que governam o assumpto de jurisdicção e competencia, que, na subdivisão do direito processual, entra no capítulo da organização judiciaria. Em direito transitorio, a materia de jurisdicção e competencia rege-se por principios ou canones especificos.

E' o primeiro que a lei nova retroage acerca da hierarchia e composição interna dos juizes e tribunaes, assim em relação aos processos pendentes como aos processos a iniciar.

"Che le nuove leggi intorno alla gerarchia delle pubbliche autoritid e magistrature, ed alla interna composizione di ciascuna di queste, debbansi applicare non meno alle procedure già avviate, che a quelle da avviarsi, è ovvio principio, essendo cosa evidente che le autorità pubbliche sono istituite dallo Stato per ragione di pubblico interesse, $e$ che $i$ privati, lungi dall'avere diritto di procedere piuttosto davanti ad un'autorità che 
ad un'altra, e composta $e$ ordinata in un dato modo, anzichè in un altro, debbono riguardare. come affatto indifferente ai loro interessi ciò che la legge statuisce su tutti questi punti". (GABBA: Ibid., pag. 463) .

A lei nova é essencialmente retroactiva pelo que respeita á organização e composição interna das auctoridades e tribunaes judiciarios, assim como pelo que toca ás suas attribuições e actividade, isto é, á jurisdicção e competencia.

Relativamente ao thema de jurisdicção e competencia, ha uma corrente de interpretes que distinguem entre processos ainda não instaurados e processos pendentes, ensinando que em relação aos primeiros applicam-se as leis novas retroactivamente, sem attenção a ser o direito, objecto do pleito, adquirido antes ou depois de entrarem em vigor; mas que, quanto aos segundos, não ha retroactividade.

Por que, quanto a estes (processos pendentes), a cujo respeito já está firmada a competencia de modo irrevogavel, a lei nova não pode ser retroactiva, por virtude do constante principio que os legisladores romanos tiveram o cuidado de consagrar por uma disposição formal na Lei 30 , Dig. De Judiciis, a saber, que todo processo deve terminar onde começou - Ubi acceptum est semel judicium, ibi et finem accipere debet; por esse principio e por ser canone fundamental na doutrina da retroactividade que os actos já consummados não podem ser considerados pela lei nova como inexistentes. A determinação da competencia é a primeira indagação que se faz em todo o processo e, verificada que seja, o processo continua onde se abrir a instancia, sem mais retorno a este argumento.

Foi esta a licção original de MerLIn no Répertoire, $v b$. Competence $\$ I I I$ e que a Merlin copiou GabBa em pag. 468 do cit. IV vol., a GabBa João Monteiro no $\S 8$ da Theoria do Processo e a João Monteiro Aureliano de Gusmão na licção XII do seu Processo Civil e Commercial. 
Foi manifesto equivoco destes grandes mestres, aliás inadvertidamente repetido por outros escriptores de menor tomo.

Não auctoriza semelhante modo de vêr a lei 30 Dig. De Judiciis; pelo contrario impõe e preceitua conclusão opposta.

Tal lei pertence ao titulo do Digesto DE JUDICIIS ET' $U B I$ - dos juizes e do lugar ou fôro perante quem $e$ onde devem correr as acções —; quer dizer, cogita da competencia territorial, da competencia relativa, da competencia de fôro, da qual não pode a parte declinar, ainda que mude de morada, de residencia, de domicilio ou de qualidade no decorrer da lide, porque ubi acceptum est semel judicium ibi et finem accipere debet.

E' uma lei complementar e integrante da de n. 7 do mesmo titulo, onde isto está dicto com inexcedivel clareza: si quis posteaquam in jus vocatum, miles vel alterius fori esse coeperit, in ea causa jus revocandi non habebit, quasi preventus - não tem direito de declinar do fôro aquelle que, citado para responder perante seu juiz, fôr depois chamado para outro fôro ou tomar o partido das armas, visto estar preventa a jurisdicção.

A lei 30 tem, como escreve Matrinolo,

"sua spiegazione e limitazione nella precedente legge 7.a dello stesso titolo; si applica cioè esclusivamente alla competenza per raggione di territorio e concerne soltanto quel cambiamenti che avvengono nella dimora, nella residenza o nel domicilio delle parti, ovverso nella mutata qualitá per cui le dette parti stanno in giudizio".

Isto foi sempre de constante e pacifica jurisprudencia na Italia, accrescenta o insigne processualista; tambem entre nós, podemos dizer e exemplificar com a passagem da competencia federal para a estadual por virtude da eliminação constitucional da alçada daquella pela residencia das 
partes em Estados differentes, assim como com o desmembramento de comarcas no Estado, casos em que as causas divisorias se transferiram para a justiça local e para as das novas comarcas, embora não fossem supprimidas nem privadas de jurisdicção as auctoridades anteriores (Conf. MAT'TIRolo: Trattato di Diritto Giudiziario Civile, 5. ${ }^{\mathrm{a}}$ ed., vol, I, not. 2 ao n. 125. DALlLoz: Répert. vb. Lois, n. 348).

Quanto ao argumento deduzido do principio fundamental da doutrina da retroactividade, de que os actos consummados não podem ser alcançados ou nullificados pela lei nova, não é menor, neste topico, o equivoco. São esses mesmos auctores equivocados que firmam o principio obvio que, relativamente ás leis de jurisdicção ou competencia de attribuição, não ha direito adquirido senão pelo que toca aos actos passados e não no que concerne aos futuros.

“essendo COSA EVIDENTE che le autoritá publiche sono istituite dallo stato per ragione di pubblico interesse e che $i$ privati, lungi dall'avere diritto die procedere piuttosto davanti ad una autorita che ad un'altra, debbono riguardare come affato indifferente ai loro interessi ciò che la l'́gge statuisce su tutti questi punti" (GABBa: Ibid.)

O proprio Merlin, em cuja esteira têm deslizado tantos e tão conspicuos tratadistas, salientou com grande sabedoria que os processos tem uma natureza successiva e que, em consequencia desta successividade, os actos que os compõem, si estão consummados, pertencem ao passado e não são attingidos pela lei nova, si ainda não foram praticados, pertencem ao futuro e são por ella alcançados (RÉPERT. $\iota b$. Effet Rétroactif sect III $\S$ VII).

Foi inapropositadamente que se procurou colorar a profligada erronia com um parecer nosso (Rev. dos Trib., 68/37); parecer que versava sobre uma divisão já finda e em que se tratava de executar a sentença nella proferida. Era evidente que a execução, para entrega do lote que coube 
a um condividente, devia ser requerida ao juiz que fez a divisão e effectuada, mediante precatoria delle, pelo juiz da comarca para onde se desmembrou o immovel.

Em conclusão, em assumpto de competencia de attribuição, a lei nova applica-se tanto aos processos proponendos quanto aos pendentes, respeitados, em relação a estes, os actos e termos já consummados, bem como os que delles forem immediata e natural consequencia. 